Administrative Issues Journal: Connecting Education, Practice, and Research, Summer 2020,

Vol. 10, No. 1.46 - 57: DOI: 10.5929/2020.10.1.4

\title{
MASTERING CRITICAL THINKING COMPETENCIES IN ONLINE GRADUATE CLASSES
}

\author{
Dr. Douglas Hermond Ph.D. \\ Prairie View A\&M University \\ Dr. Tyrone Tanner Ed.D. \\ Prairie View A\&M University
}

\begin{abstract}
Many colleges of education have embraced online course delivery as an expeditious means of delivering graduate programs. It behooves us to ensure that this delivery method does not compromise our ability to provide these students with necessary critical thinking competencies. This research was designed to determine the degree to which participants in online graduate courses value critical thinking and the degree to which they developed these skills. The results indicated that students both valued understanding, judgment, caution/skepticism, originality, and reflection/action, and developed them in their online classes. The implications confirm that online platforms allow for the development of critical thinking competencies.
\end{abstract}

Keywords: critical thinking, online programs, educator preparation

G raduate programs are expeditiously moving to new technologies to deliver traditional courses, with a preponderance of those "new" technologies being online course delivery. In fact, the Center for Online Education (2019) estimates that 33 percent of college students take at least one online course. The percentage increases to 51 percent in the midst of pandemics such as COVID-19 (AACSB, 2020). Considering the increasing growth in online platforms, many ongoing investigations are exploring whether these courses are being delivered with quality and whether they yield the same cognitive outcomes as traditional face-to-face courses, especially since previous studies suggests failure and withdrawal rates for online courses exceed those of face-to-face courses (Topper and Lancaster, 2016; Community College Research Center, 2013).

Currently, a focus on undergraduate education dominates the literature on the efficacy of online learning, as Bowden (2012) indicates. One distinction between undergraduate and graduate programs is that, as Lohr and Haley (2017) report, many students in graduate programs are unfamiliar with the selfdiscipline demands of online programs, which may well impact their level of engagement. Most importantly, researchers have shown that student engagement is paramount if students are to remain motivated (Bloomberg, 2020). An earlier study by Dunn, Rakes and Rakes (2014) makes the connection 
between self-regulation (motivation), critical thinking, and age on the online graduate student's propensity to seek help. This means that online graduate programs may need to employ motivational strategies that differ from those in face-to-face interactions. Failure to do so will not only contribute to the withdrawal rate, but graduate students may not master the skills requisite for success in the marketplace.

Explicit, or implicit, in the mission or strategic intention of most graduate degree programs is the expectation that their students enhance their critical thinking skills. This emphasis is driven, in part, by the continuing discussion surrounding the need for graduates to be workforce ready, an idea captured by the $21^{\text {st }}$-century Sustainable Goals, as reported by Care, Kim, Vista, and Anderson, (2018). The goals require that "education systems ... equip learners with competencies such as problem solving, collaboration, critical thinking, and communication" (p. 3). This investigation highlights critical thinking as a salient skill to be investigated further.

Ever since the work of Glaser (1941), critical thinking has received near universal acceptance; thus, it is now an unquestioned part of our daily vernacular. Educators and scholars have internalized the notion that, as Paul (1984) articulated, critical thinking is crucial to the completeness of our intellectual, emotional, and moral development. It is also society's expectation that schools serve as the incubator for its citizens' development of critical thinking skills. As Noguera (2010) recognized, "schools have an essential role to play in renewing and invigorating American democracy by encouraging critical thinking and civic engagement" (p. 14). Consequently, educators serve as the purveyors of critical thinking, which heightens the importance of educators developing critical thinking skills. As Green and Yu (2018) concurred, educator training programs are the most likely avenues for educators to develop this skill. This brings us to the training that educators receive at colleges and universities.

In 2009, several College of Education deans met at the American Association of Colleges for Teacher Education (AACTE) to conjecture on how their educator preparation programs might effectively implant $21^{\text {st }}$-century knowledge and skills into their programs. The result was a seminal draft of action plans that were buttressed by the belief that they must prepare "graduates for a world in which academic content mastery and skills such as critical thinking, communication, technology literacy, and collaboration are required for success in college, life; and career" (Greenhill, 2010, p. 8). Given this realization, it is hard to find a college of education that does not have critical thinking as an explicit or implicit outcome of their educator preparation programs.

A challenge educator preparation programs face is the assessment of the degree to which their programs foster the acquisition of critical thinking skills. For preparation programs which offer online programs to respond to the needs of digital citizens, who prefer learning via online platforms, the assessment is equally important. As online programs and courses become more prevalent, it becomes imperative this course delivery mode develops future educators' critical thinking skills. Consequently, the researchers of this investigation seek to determine the degree to which participants in online graduate courses value critical thinking and their perceived degree to which they are developing these skills.

\section{Exploring Dimensions of Critical Thinking}

So, what exactly is critical thinking? Given the absence of a universally accepted definition, we adopt Ennis" description of critical thinking as "reasonable, reflective thinking that is focused on deciding 
what to believe or do" (2011, p. 5). As applied to the context of Educational leadership, ASCD defines critical thinking, as "examining possibilities carefully, fairly, and constructively-focusing your thoughts and actions by organizing and analyzing possibilities, refining and developing the most promising possibilities, ranking or prioritizing options, and choosing certain options" (Treffinger, 2008, p. 1).

More specifically, we coalesce the seven distinctions of critical thinking that Moore (2013) refined into five domains: understanding, judgment, caution/skepticism, originality, and reflection/action. These complement Bloom's revised cognitive taxonomy that include, in order: remembering, understanding, applying, analyzing, evaluating, and creating (Armstrong, 2001). A brief synopsis revealed that the literature is supportive of the notion that critical thinking encompasses the five aforementioned domains. These are diagrammed in Figure 1, below.

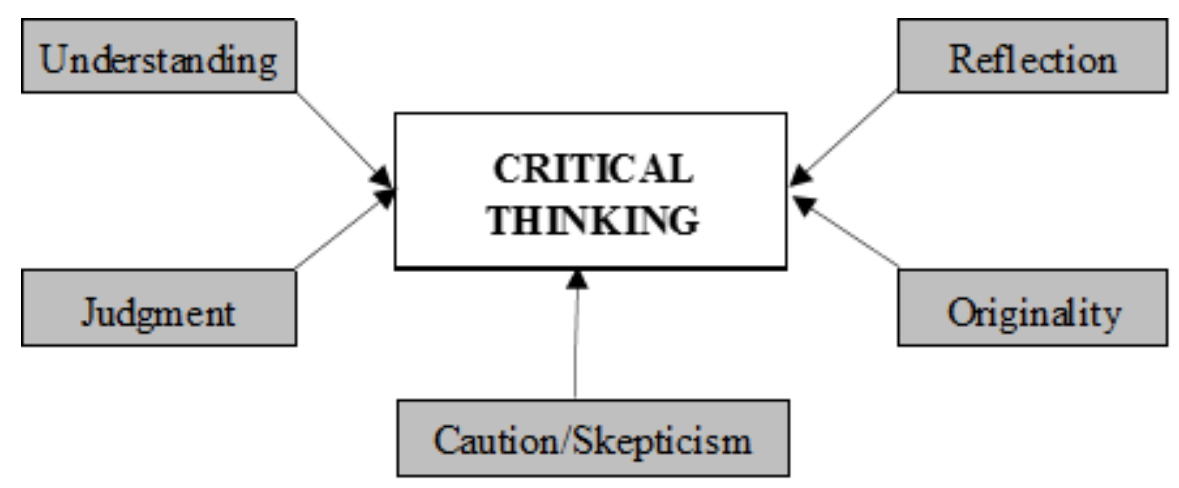

Figure 1. Critical Thinking Domains

Understanding. If critical thinking requires a focus on the most promising possibilities in solving problems, it stands to reason that the critical thinker must possess some foundational knowledge of the problem under investigation. McPeck (1981), referred to this basic understanding as the skills necessary to reflect on an activity. Alfaro-LeFevre (2017) succinctly stated that "developing critical thinking starts with having a good understanding of what IS" (p. 2).

Judgment. Implicit in our comprehension of critical thinking is the notion that the critical thinker brings valuable judgment to the thinking process. In fact, in 1990, the American Philosophical Association convened an expert panel to reach consensus about the role of critical thinking. Their definition specifies that critical thinking includes "self-regulatory judgment" (Facione, 1990, p. 3). Similarly, Casey (2012) expounds that the "critical" in critical thinking, by its very definition, involves a "form of mental activity relating to judgements, their production, their evaluation, their validation" (p. 44). The strong inference, then, is that judgment is an integral part of the critical thinking process.

Caution and Skepticism. In his seminal 1981 text, McPeck regards caution and skepticism as the "most notable characteristic of critical thought" (p. 6). He aptly suggests that the wise application of skepticism, coupled with experience (i.e. understanding), helps the critical thinker arrive at the best solutions. Casey (2012) elaborates on this idea of skepticism by suggesting that critical thinking requires that we "challenge existing information, and arriv[ing]e at a considered conclusion on the basis of this information, 
developing your own arguments, deconstructing ideas, being objective rather than subjective, moving from evidence to conclusion" (p. 25).

Originality. Shively, Stith, and Rubenstein (2018) reminds educators that originality refers to the ability to develop new ideas or substantially build upon current ideas but with a unique perspective. In connection with this perspective, Moore (2013) records that several of the participants in his examination of critical thinking expressed the idea that critical thinking involves both the challenging of ideas, and the propensity to create new ones.

Reflection. As stated earlier, Ennis (2011) reports that critical thinking involves "reflective and reasonable thinking that is focused on deciding what to believe or do," (p. 5). This complements the result of Moore's (2013) investigation about scholars' definition of critical thinking, in which self-reflection is an essential component.

Essentially, the literature, in large measure, supports the idea that critical thinking encompasses understanding, judgment, caution/skepticism, originality, and reflection. However, we would be remiss, if we also did not acknowledge that the literature also supports additional notions of critical thinking, which are not the primary subject of this investigation. In this study we seek to explore the following research questions:

\section{Research Questions}

1. To what degree do participants in online graduate courses value critical thinking? This is intended to determine the extent to which graduate educational leadership students viewed critical thinking concepts as valuable to them.

2. To what degree do participants believe that they are mastering critical thinking skills in their online courses? Here we are eager to discover whether participants further developed critical thinking as a result of their online courses.

3. Are there differences between participants' value of critical thinking and their mastery of critical thinking as a result of the online course(s) they were taking? At this point, we are curious about any possible discrepancy between participants' value of critical thinking, and their perceived level of exposure.

\section{Method}

In an effort to measure the degree to which participants in online graduate courses value critical thinking and their perceptions of the degree to which they are developing these skills, the researchers administered a 16-item instrument designed around these five domains, to 30 graduate students taking online classes from a university in southeast Texas, during the culminating course in their educational leadership preparation program. These students were recruited to participate in the study because they had completed all coursework and were finalizing their internship. Given their completion of all preparation requirements, they were likely best equipped to reflect on the breadth of the entire program. The data were collected over a period of a month via an online survey. The specific items, gathered from Ennis (1987) used to measure these five domains were: 


\author{
Understanding \\ - $\quad$ Grasping the meaning of ideas presented in the course \\ - $\quad$ Understanding the intentions/purposes \\ - $\quad$ Recognizing the context in which ideas are generated
}

Judgment

- Evaluating whether the ideas/concepts presented in the course are accurate

- $\quad$ Assessing whether the ideas/concepts presented in the course are useful

- $\quad$ Considering if the ideas/concepts presented in the course are good or bad

\title{
Caution/Skepticism
}

- $\quad$ Examining whether I should accept the information presented in class(es)

- $\quad$ Critiquing my own beliefs and assumptions about ideas/issues raised in the course

- $\quad$ Challenging the views and perspectives of others in the class

\section{Originality}

- Generating my own theories and perspectives

- $\quad$ Drawing connections across different ideas

- $\quad$ Using reason to construct my own ideas

- $\quad$ Reaching my own conclusions about issues

\section{$\underline{\text { Reflection and Action }}$}

$\begin{array}{ll}\text { - } & \text { Being aware of how I arrived at my conclusions } \\ \text { - } & \text { Developing the ability to defend my conclusions } \\ \text { - } & \text { Determining to act on my conclusions }\end{array}$

Participants were required to answer each item twice. First, they shared the degree to which they value each statement. Next, they were asked to assess the degree to which the online course(s) they were presently taking helped them master the ideas presented in each item. We used a five-point Likerttype scale for each item, ranging from Strongly Agree to Strongly Disagree.

\section{Results}

Before attempting to answer our research questions, we conjectured about the stability and validity of the instrument. We were cognizant of the face content validity of the instrument in that the items were gleaned directly from Ennis' (1987) descriptions of the five constructs. However, as a quality check, we conducted an item-factor correlation between each item and the construct it was designed to measure, validating our confidence in the instrument. The item-factor correlations ranged from a low of 0.675 to a high of 0.919 , with most relationships settling in the 0.80 range. Second, we sought to establish the reliability of the instrument via Cronbach's alpha. This yielded an alpha coefficient of 0.897 . Thus, we proceeded with the examination of the research questions with the confidence that we measured what we purported to measure, using a stable instrument.

Our first two research questions are descriptive in nature. We received responses from 30 of the 100 or so participants. To answer these first two questions, we generated bar graphs to report students' 
scores for each of the five critical thinking domains. Figure 2 below indicates that participants rated all five domains as valuable. The "Understanding" domain secured the highest numeric value ( 4.56 out of a possible 5.00), while "Caution" had the lowest score (4.14). To determine if significant differences existed across the factors, we conducted a repeated measures ANOVA. Here, the dependent variables were scores of the critical thinking domains, while the independent variable constituted the five within-subject domains. The results indicate that the scores for these five domains were not statistically significantly different from each other.

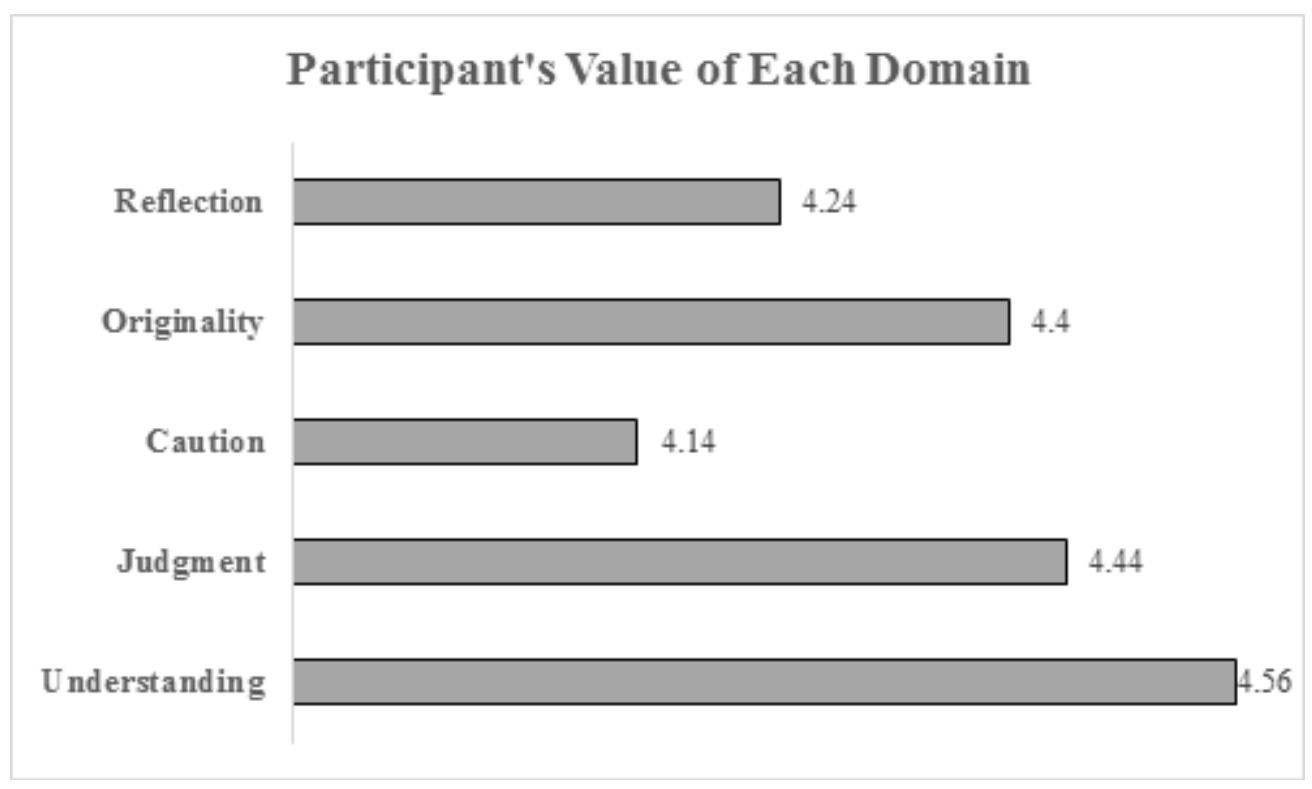

Figure 2: Participants' Value of Critical Thinking

As Figure 3 indicates below, participants are equally pleased with the degree to which they were exposed to critical thinking in their classes. The "Understanding" domain had the highest numeric score (4.56) while "Caution" again had the lowest score (4.12). It was likewise clear, based on our repeated measures ANOVA, that these domain scores did not differ significantly from each other. Our conjecture about the "Caution" domain is that participants do not value the idea of questioning the authenticity of the information that they are exposed to, or they are not willing to critique their own assumptions and the assumptions of others. Perhaps the lack of the interaction with other students, given that these classes were online, also limited their ability to practice this skill in the class. 


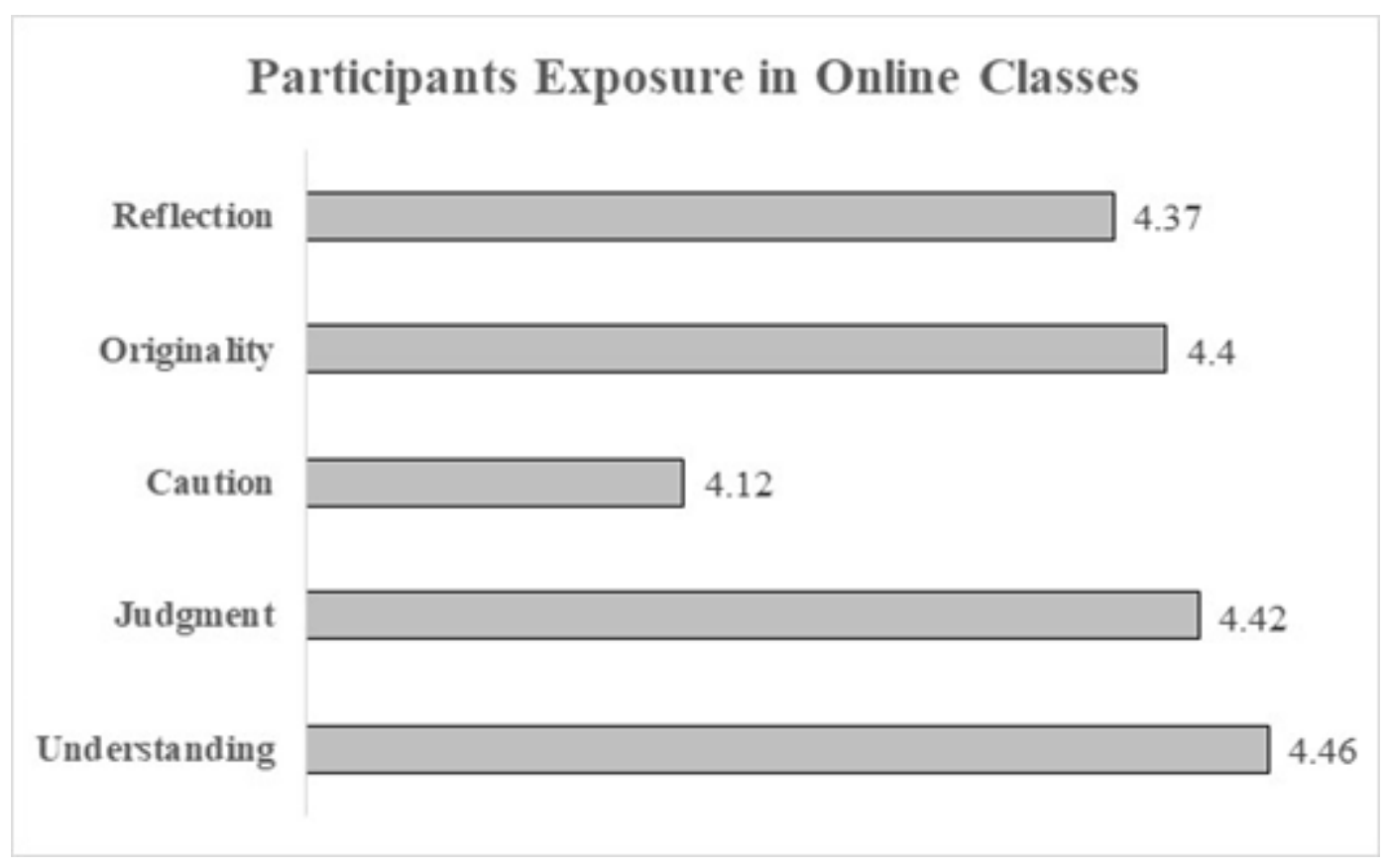

Figure 3. Participants' Exposure to Critical Thinking

Our final question was designed to determine if participants' value of these critical thinking concepts differed substantially from the degree to which they were exposed in their online graduate course(s). Along with a graphical comparison of the two sets of answers, we conducted a paired t-test for each set of scores. For example, we conducted this test on "Understanding" between the value scores and the exposure scores. Figure 4 shows these comparisons.

Note again, that the scores all exceeded a "4" out of a possible "5." The t-test for each pair indicated that the pairs were not statistically significantly different. The results of all five domains are shown in Table 1 below. Note that whereas none of the differences were statistically significant from each other, the greatest range in score was for the "Reflection" domain, which was the only domain in which the exposure score exceeded the value score. Again, we were drawn to the realization that these scores were not different from each other, indicating that the delivery of these domains matched participants' value, both of which were high. 


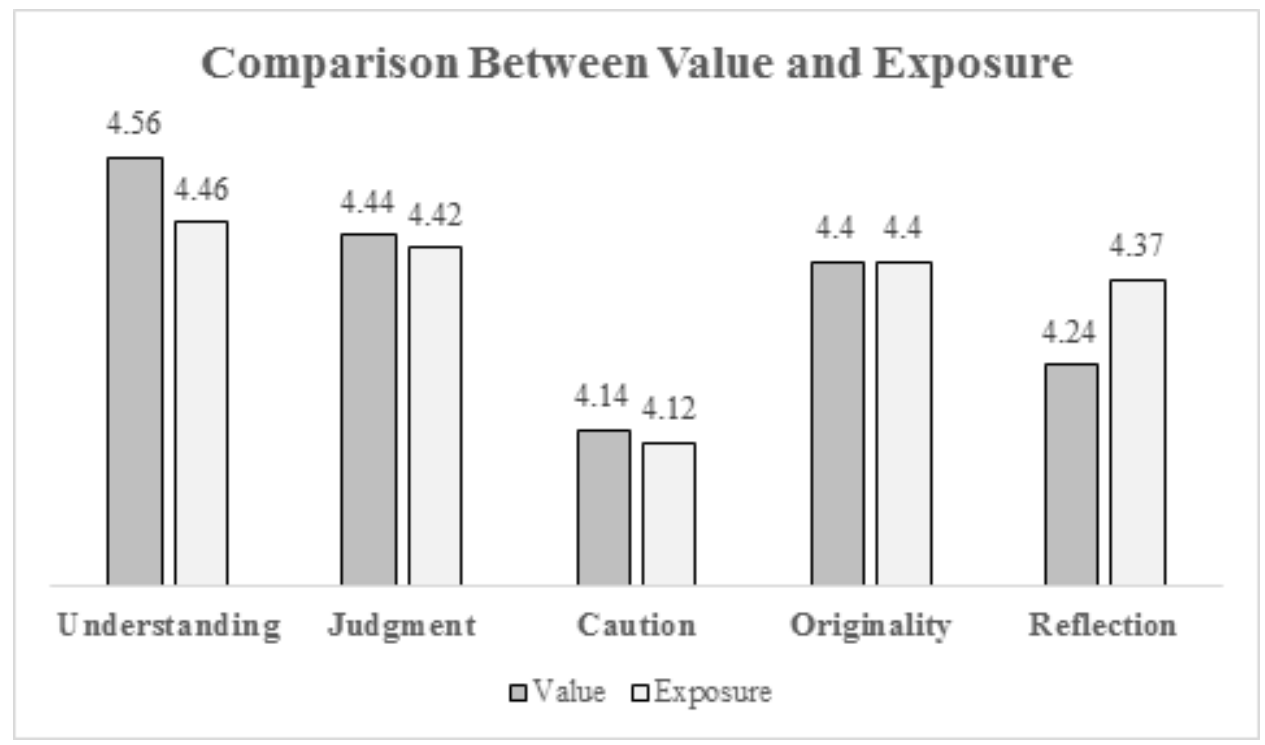

Figure 4. Comparison of Critical Thinking Domain Scores

Table 1. Paired T-Tests for Five Domains

\begin{tabular}{|c|c|c|c|c|c|c|c|}
\hline & & \multicolumn{3}{|c|}{ Paired Differences } & \multirow[b]{2}{*}{$\mathbf{t}$} & \multirow[b]{2}{*}{ df } & \multirow[b]{2}{*}{$\begin{array}{l}\text { Sig. (2- } \\
\text { tailed) }\end{array}$} \\
\hline & & Mean & $\begin{array}{c}\text { Std. } \\
\text { Deviation }\end{array}$ & $\begin{array}{l}\text { Std. Error } \\
\text { Mean }\end{array}$ & & & \\
\hline $\begin{array}{c}\text { Pair } \\
1\end{array}$ & $\begin{array}{l}\text { UnderstandA- } \\
\text { UnderstandB }\end{array}$ & 0.095 & 0.443 & 0.084 & 1.137 & 27 & .265 \\
\hline $\begin{array}{l}\text { Pair } \\
2\end{array}$ & JudgmentA - JudgmentB & 0.022 & 0.510 & 0.093 & .239 & 29 & .813 \\
\hline $\begin{array}{l}\text { Pair } \\
3\end{array}$ & CautionA - CautionB & 0.022 & 0.495 & 0.090 & .246 & 29 & .807 \\
\hline $\begin{array}{l}\text { Pair } \\
4\end{array}$ & $\begin{array}{l}\text { OriginalityA - } \\
\text { OriginalityB }\end{array}$ & 0.000 & 0.415 & 0.076 & .000 & 29 & 1.000 \\
\hline $\begin{array}{l}\text { Pair } \\
5\end{array}$ & $\begin{array}{l}\text { ReflectionA - } \\
\text { ReflectionB }\end{array}$ & $\begin{array}{c}- \\
0.122\end{array}$ & 0.719 & 0.131 & -.931 & 29 & .360 \\
\hline
\end{tabular}




\section{Conclusions}

Our investigation was designed to determine the degree to which participants in an online class valued critical thinking, and their exposure to critical thinking skills in their graduate program. As a consequence, we were able to conclude the following:

a. Our participants value critical thinking as essential in their learning process. For all five dimensions of critical thinking, their average value is greater than 4.0 , out of a possible score of 5.0.

b. Our participants are also quite satisfied with the degree to which they are exposed to these competencies in their online courses.

The results also validated the integrity of the instrument we used as stable along the five critical dimensions of understanding, judgment, caution, originality, and reflection.

Whereas these are encouraging results, we recognize that this is just the first salvo in our assessment of critical thinking. Here are additional investigations that loom ahead.

1. A comparison of scores between online, hybrid, and face-to-face courses,

2. Identification of specific activities that facilitate the acquisition of these skills in the online courses, and

3. Many of the degree-seeking candidates in the online courses we surveyed will lead or influence diverse populations. We need to ensure that these skills translate in the marketplace to a broad population.

Finally, we hope it is apparent that the value of this investigation is that the information gleaned will advance our knowledge of the emphasis that graduate students in an online program place on critical thinking, and the degree to which this medium accommodates the acquisition of this skill. This is rather prescient in this season of COVID-19 in at least two ways.

First, for those prospective leaders who may have found the technology and associated learning to be nascent, the change in learning modality for their students from face-to-face to virtual as a result of quarantine policies, is further enhancing their distance learning proficiency. Second, and more important, those educators who lead poorly-resourced schools have had to develop innovative strategies to meet their students' learning needs. To do so, they had to quickly develop an understanding of the learners' needs and make judgments about the best courses of action from among less-than-ideal alternatives. Next, they had to structure original and innovative ways of helping teachers deliver instruction, and quickly gather information to reflect on what works or what needs to be improved. These are all vital features of a critical thinker.

We concur with Green and $\mathrm{Yu}$ (2018) that educator preparation programs should serve as laboratories where prospective leaders can enhance their critical thinking skills. We are encouraged by the perspective that Dunn and Rakes (2015) presented about the potential for training techniques to enhance students' ability to develop this viable skill. We therefore conclude that the online platform is not a hindrance, but a necessary medium that allows prospective leaders access to both content learning and critical thinking. 


\section{References}

AACSB Blog. (2020). AACSB Quick-Take Survey on COVID-19: Online/Virtual Instruction Findings.

Retrieved from https://www.aacsb.edu/blog/2020/march/aacsb-quick-takesurveyon-covid-19online-virtual-instruction-findings

Alfaro-LeFevre, R. (2017). Critical thinking, clinical reasoning, and clinical judgment, ( $6^{\text {th }}$ ed.). Philadelphia, PA: Elsiver.

Armstrong, P. (nd). Bloom's Taxonomy. Vanderbilt University Center for Teaching. Retrieved from https://cft.vanderbilt.edu/guides-sub-pages/blooms-taxonomy/

Bloomberg, L. (2020). Developing a learning community through an online university' community engagement platform: an analysis of the experiences of students and faculty. International Journal of Online Graduate Education, 3(1), 1-24

Bowden, R. (2012). Online graduate education: developing scholars through asynchronous discussion. International Journal of Learning in Higher Education, 24(1), 52-64.

Care, E., Kim, K., Vista, A., \& Anderson, K. (2018). Education system alignment for $21^{\text {st }}$ century skills: focus on assessment. Washington, DC: The Brookings Institution. Retrieved from https://files.eric.ed.gov/fulltext/ED592779.pdf

Casey, G. (2012). Thinking Critically about Critical Thinking. In M. F. Shaughnessy (Ed.), Critical thinking and higher order thinking : A current perspective (23-40). New York, NY: Nova Science Publishers, Inc.

Center for Online Education. (2019). Online college students by the numbers. Retrieved from https://www.onlinecolleges.net/for-students/online-college-students-by-the-numbers/

Community College Research Center. (2013). What we know about online course outcomes. Retrieved from http://ccrc.tc.columbia.edu/media/k2/attachments/what-we-know-about online-course-outcomes.pdf

Dunn, K., \& Rakes, G. (2015). Exploring online graduate students' response to online self-regulation training. Journal of Interactive Online Learning, 13(4), 1-22.

Dunn, K., Rakes, G., \& Rakes, T. (2014). Influence of academic self-regulation, critical thinking, and age on online graduate students' academic help seeking. Distance Education, 35(1), 75-89.

Ennis, R. (2011). Critical thinking: reflection and perspective, part 2. Inquiry: Critical Thinking across the Disciplines, 26(2), 5-19. 
Facione, P. (1990) Critical thinking: A statement of expert consensus for purposes of educational assessment and instruction. Research findings and recommendations. Millbrae, CA: California Academic Press.

Glaser, E. (1941). An experiment in the development of critical thinking. New York, NY: Columbia University Bureau of Publications, Teacher's College.

Greene, J., \& Yu, S. (2018). Educating critical thinkers: the role of epistemic cognition. Policy Insights from the Behavioral and Brain Sciences 2016, 3(1), 45-53.

Greenhill, V. (2010). 21st century knowledge and skills in educator preparation. Washington, DC: AACTE, Partnership for $21^{\text {st }}$ Century Schools. Retrieved from https://files.eric.ed.gov/fulltext/ED519336.pdf

Lohr, K., \& Haley, K. (2017). Using biographical prompts to build community in an online graduate class. Adult Learning, 29(1). Retrieved from https://journals.sagepub.com/doi/10.1177/1045159517735597

McPeck, J. (1981). Critical thinking and education. New York, NY: Routledge Library Editions.

Moore, T. (2013). Critical thinking: seven definitions in search of a concept. Studies in Higher Education, 38 (4), 506-522.

Noguera, P. (2010). A new vision for school reform. The Nation, 290 (23), 11-14.

Paul, R. (1984). Critical thinking: fundamental to education for a free society. Educational Leadership, 42 (1), 4-14.

Shively, K., Stith, K., \& Rubenstein, L. (2018). Measuring what matters: Assessing creativity, critical thinking, and the design process. Gifted Child Today, 41, 149-158.

Topper, A., \& Lancaster, S. (2016). Online graduate educational technology program: an illuminative evaluation. Studies in Educational Evaluation, 51, 108-117.

Treffinger, D. (2008, Summer). Preparing creative and critical thinkers. ASCD Thinking Skills NOW, 65. Retrieved from http://www.ascd.org/publications/educational leadership/summer08/vol65/num09/Preparing-Creative-and-Critical-Thinkers.aspx 


\section{About the Authors}

Dr. Douglas Hermond, Ph.D. (dshermond@pvamu.edu), is a professor in Prairie View A\&M University's Department of Educational Leadership and Counseling, where he twice served as the coordinator of the doctoral program in Educational Leadership. His research focuses on Leadership Evaluation and Culturally Responsive Leadership. Prior to his current role, Dr. Hermond was a senior researcher with Decision Information Resources, a consulting firm that caters to the U.S. Departments of Education, Labor, and Health and Human Services. He also served on the faculty at the University of Houston.

Dr. Tyrone Tanner, Ed.D. (tytanner@pvamu.edu), is the Executive Director of Prairie View A\&M University's Northwest Houston Center and Professor of Educational Leadership. His research agenda focuses on closing achievement gaps, retention, and graduation in P-16 settings; building strong parent/school partnerships; dispelling deficit model thinking; diversity, and culturally responsive leadership and teaching. He has more than 30 published books/articles and has provided professional development to many school districts and community organizations. 